Original Research Article

\title{
Variation of cost among anti-malarial drugs available in Indian market
}

\author{
Prasan R. Bhandari ${ }^{1 *}$, Apeksha Bhandary ${ }^{2}$
}

${ }^{1}$ Department of Pharmacology, SDM College of Medical

Sciences and Hospital, Dharwad, Karnataka, India

${ }^{2}$ Regional Medical Liaison

AstraZeneca, Mumbai, India

Received: 10 September 2019

Revised: 11 October 2019

Accepted: 12 October 2019

\section{*Correspondence to:}

Dr. Prasan R. Bhandari, Email: prasangeeta2012@ gmail.com

Copyright: (C) the author(s), publisher and licensee Medip Academy. This is an openaccess article distributed under the terms of the Creative Commons Attribution NonCommercial License, which permits unrestricted noncommercial use, distribution, and reproduction in any medium, provided the original work is properly cited.

\begin{abstract}
Background: There are numerous brands of antimalarial existent in the market. Expensive drugs could result in financial drain that causes reduced compliance or even non-compliance. Non-adherence to therapy could consequently cause partial treatment that leads to higher morbidity and in certain cases mortality too. Thus this evaluation was conducted to measure the cost disparity of malaria therapy.

Methods: The maximum and minimum price of each brand of the drug in Indian rupee rate was noted by using the latest edition of current index of medical specialities. The cost ratio and the percentage cost variation for individual drug brands were calculated.

Results: The analysis of data reflected a considerable cost variation among antimalarial drugs. Chloroquine DS $500 \mathrm{mg}$ showed the highest cost ratio and cost variation (cost ratio $=15.3$ and $\%$ cost variation $=1434)$. Overall injectable antimalarials showed considerable cost variation as compared to oral antimalarial agents.

Conclusions: The maximum variation shown by oral antimalarial was found to be for chloroquine DS 500 tablet. But there was significant price variation among injectable antimalarial. Injectable antimalarials are often the choice of drug when dealing with critically ill malaria patients specially when suffering from complicated malaria. So, such significant price variation creates burden on poor patients economically which leads to non-compliance and hence increased morbidity and mortality due to incomplete treatment.
\end{abstract}

Keywords: Antimalarial drugs, Cost ratio, Percent cost variation, Indian market

\section{INTRODUCTION}

Malaria has been a source of constant threat in India for centuries. Particulars of this disease are even mentioned in the primeval Indian medical works like the Atharva Veda and Charaka Samhita. Through the later parts of nineteenth and early twentieth centuries, approximately one-fourth of India's population was afflicted from malaria, mainly in the states like Punjab and Bengal. ${ }^{1,2}$

The government of India launched the National Malaria Control Programme in April 1953. Firstly the programme was an achievement since the number of malaria cases considerably dropped. ${ }^{3}$
The programme was reformed to National Malaria Eradication Programme in 1958. The occurrence plunged more to a meager 49151 cases, with no deaths by $1961 .{ }^{4}$

However, later the programme underwent frequent setbacks and the number of patients of malaria began to increase again. In the second half of 1960s malaria patients in cities began to dramatically increase. Consequently, in 1976, 6.45 million patients were recorded by the National Malaria Eradication Programme, maximum ever since reappearance. Malaria, initially primarily was a rural disease, differentiated underneath the burden of advances into several ecotypes. These ecotypes have been recognized as forest malaria, urban malaria, rural malaria, industrial malaria, border 
malaria and migration malaria. Additionally, malaria in the 1990s has reverted with novel types not observed throughout the pre-eradication times. These are the vector resistant to insecticides, exophilic vector behaviour, extensive vector breeding grounds due to urbanization and industrialization, resistance in $P$. falciparum to chloroquine and other anti-malarial drugs; and human resistance to chemical control of vectors. 1,5

As per the world malaria report 2014, 22\% (275.5 m) of India's population live in high transmission $(>1$ case per 1000 population) areas, $67 \%(838.9 \mathrm{~m})$ live in low transmission ( 0 - 1 cases per 1000 population) areas and $11 \%(137.7 \mathrm{~m})$ live in malaria-free ( 0 cases $)$ areas. In 2013, 0.88 million cases have been recorded, with 128 million tests being conducted on the suspected cases, with $P$. falciparum causing $53 \%$ and $P$. vivax causing $47 \%$ of the infections. The incidence of malaria in India accounted for $58 \%$ of cases in the South-East Asia Region of WHO. ${ }^{1,6}$

Currently National Vector Borne Disease Control Programme indicates 0.7-1.6 million confirmed cases and 400-1,000 deaths annually.

Agreed that due to the enormousness of malaria in our nation, antimalarial drugs ought to be provided at government sectors and at private pharmacies at costs that will not generate monetary problem on the fundamentally underprivileged population. There are numerous products of antimalarial existing in the market. Malaria can be exceptionally lethal if not managed on time.

Patients from deprived socioeconomic families necessarily must have right to use to the right drug at the minimal price. Expensive drugs could result in financial encumbrance that consequently can lead to reduced patient compliance or even non-compliance. Noncompliance results in inadequate treatment which inclines to higher morbidity as well as mortality. There is a great disparity between the price of several brands of same generic drugs existing in India. Escalation in the patient treatment cost was observed to be related with diminished compliance to medicine. ${ }^{8}$ Price analysis is the evaluation in which assessment of costs of two or more substitute drug is prepared without regard to outcome. ${ }^{9-11}$

Indian markets are flooded with a huge number of antimalarials and the same drugs are sold under different brands which puts the prescribing physicians in a difficult state to choose the best drug for a given patient.

Studies performed earlier demonstrated a significant disparity in price of branded and generic types of same drug. $^{12,13}$

Therefore, the current study was done to estimate the price variation amid the diverse brands of antimalarial drugs existing in Indian market.
We hypothesize that by evaluating the variations in the cost of antimalarials would assist the prescribing physicians in a difficult state to choose the best drug for a given patient thereby increase the rate of complete response and improve long-term outcomes.

\section{METHODS}

This open comparative study was done in the Department of Pharmacology of a tertiary care teaching hospital in south India. The study was conducted from April to June 2019 after obtaining the ethical clearance from the Institutional Ethics Committee. Latest volume of current index of medical specialities was used to analyze the prices of anti-malarial drugs.

The cost of a particular anti-malarial drug in the same dose and dosage forms being manufactured by different companies would be compared.

The drugs manufactured by only one company or by different companies, however, in different strengths would be excluded.

The difference between the maximum and minimum costs of the same drug manufactured by different pharmaceutical companies would be calculated.

The following formula would be used to calculate the price variation.

Percentage cost variation would be calculated as follows:

$\%$ Cost variation $=\frac{\text { Maximum cost }- \text { Minimum } \cos t \times 100}{\text { Minimum cost }}$

The cost ratio i.e., the ratio between the maximum and minimum cost of the same generic anti-cancer drug would be calculated as follows:

Cost ratio $=\frac{\text { Maximum cost }}{\text { Minimum cost }}$

\section{Statistical analysis}

The findings of our observational study would be expressed as absolute numbers and percentages

\section{RESULTS}

The analysis of data reflected a considerable cost variation among antimalarial drugs. Chloroquine DS 500 mg showed the highest cost ratio and cost variation (cost ratio $=15.3$ and $\%$ cost variation =1434). Overall injectable antimalarials showed considerable cost variation as compared to oral antimalarial agents. The cost ratio and cost variation of arteether injection 150 $\mathrm{mg} / \mathrm{ml}$ was 3.0 and 200.5 respectively. Additionally, the cost ratio and cost variation of the combination of lumefantrine and artemether was 3.1 and 212.2 respectively (Table 1). 
Table 1: Cost variation of antimalarial agents.

\begin{tabular}{|c|c|c|c|c|}
\hline Drug & $\begin{array}{l}\text { Maximum } \\
\text { price per unit } \\
\text { INR }\end{array}$ & $\begin{array}{l}\text { Minimum } \\
\text { price per } \\
\text { unit INR }\end{array}$ & $\begin{array}{l}\text { Cost ratio= } \\
\text { maximum } \\
\text { price/minimum } \\
\text { price }\end{array}$ & $\begin{array}{l}\text { Cost } \\
\text { variation=maximu } \\
\text { m price }- \text { minimum } \\
\text { price/minimum } \\
\text { price } \times \mathbf{1 0 0}\end{array}$ \\
\hline Chloroquine DS 500 mg 5 tablets & 134 & 8.73 & 15.3 & 1434.9 \\
\hline Chloroquine injection/ml & 1.57 & 0.91 & 1.7 & 72.5 \\
\hline Mefloquine $250 \mathrm{mg} /$ tablet & 101 & 49.3 & 2.0 & 104.9 \\
\hline Quinine 300 mg /tablet & 60 & 42 & 1.4 & 42.9 \\
\hline Quinine 600 mg /tablet & 97 & 90 & 1.1 & 7.8 \\
\hline Arteether 150 mg/ml & 55 & 18.3 & 3.0 & 200.5 \\
\hline Artemether 40 mg/ml & 21.6 & 19.3 & 1.1 & 11.9 \\
\hline Artesunate $50 \mathrm{mg} / \mathrm{tab}$ & 27.5 & 15 & 1.8 & 83.3 \\
\hline Artesunate $60 \mathrm{mg} / \mathrm{vial}$ & 231 & 159 & 1.5 & 45.3 \\
\hline Lumefantrine 480 mg+artemether $80 \mathrm{mg}$ & 153 & 49 & 3.1 & 212.2 \\
\hline
\end{tabular}

\section{DISCUSSION}

Societies existing in developing nations pay hefty price of medicines. In our nation, approximately $80 \%$ health funding is endured by patients. ${ }^{14-16}$ The condition develops into an additional multifaceted issue because of the availability if several brands with diversity of names and costs. ${ }^{17}$ The cost deviation dons import once the cost ratio surpasses 2 and percentage cost variation goes beyond 100. Accordingly, the above scrutiny displayed that there is substantial cost difference between oral antimalarial drugs.

A study by Kumar et al demonstrated extreme deviation in oral antimalarial was observed for fixed dose combination of artemether and lumefantrine (cost ratio $>2$ 2.03 ) and $\%$ price variation $>100103.7$ while other oral drugs all showed cost ratio less than 2 and $\%$ cost variation less than 100 . However there was noteworthy price disparity amid injectable antimalarial for example there is significant cost ratio and cost variation of artemether injection $150 \mathrm{mg}$ per $2 \mathrm{ml}$ (cost ratio=16.96 and $\%$ cost variation $=1596)$.

Injectable antimalarials are frequently the optimal of drug while managing patients with critically unpleasant malaria patients particularly while afflicted by complicated malaria. Hence, such substantial cost variation produces financial encumbrance on underprivileged patients. This frequently results in nonadherence or unexpected termination of treatment that supplements on the morbidity and mortality owing to malaria. The handling physician ought to be prepared and cognizant of the inexpensive drug accessible amongst the numerous brands with the intention that the patient endures reduced liability of treatment cost. Prices of drug are organized by the drug price control order 2013 (DPCO). ${ }^{18}$

\section{CONCLUSION}

Maximum price of drugs are decided by national pharmaceutical pricing authority (NPPA) government of India in agreement with DPCO 2013. In spite of this there occurs an extensive discrepancy of drug prices within one drug with the accessibility of numerous brands. Similarly, the NPPA ought to act sternly to confirm that the costs of antimalarial drugs and their combinations are got under control with the aim that all patients notwithstanding the economical class must be capable of affording these medications and get treated totally.

Funding: No funding sources

Conflict of interest: None declared

Ethical approval: The study was approved by the Institutional Ethics Committee

\section{REFERENCES}

1. Kumar L, Dinkar JK, Mohan L, Dikshit H. Cost variation analysis of antimalarial drugs available in India. Int J Res Med Sci. 2017;5(9):4051-4.

2. Tren R. Malaria and Climate Change. Working Papers Series: Julian Simon Centre for Policy Research. October 2002. Available at: http://www .libertyindia.org/pdfs/malaria_climatechange2002.pdf . Accessed on 1 September 2019.

3. PB Health. National Vector Borne Disease Control Programme. Available at: http://pbhealth.gov.in/pdf/ malaria.pdf. Accessed on 1 September 2019.

4. Dash AP, Valecha N, Anvikar AR, Umar A. Malaria in India: challenges and opportunities. J Biosci. 2008;33:583-92.

5. Sharma VP. Re-emergence of malaria in India. Indian J Med Res. 1996;103:26-45.

6. WHO. World Malaria Report 2014. WHO, Geneva. 2014. Available at: http://apps.who.int/iris/bitstream/ 10665/144852/2/9 789241564830_eng.pdf. Accessed on 1 September 2019. 
7. Kumar A, Valecha N, Jain T, Dash AP. Burden of malaria in India: retrospective and prospective view. Am J Trop Med Hyg. 2007;77(6):69-78.

8. Malaria situation. National Vector Borne Disease control Programme. Available at http://nvbdcp.Gov .in/Doc/mal_situation_Jan2015.pdf. Accessed on 1 September 2019.

9. Eaddy MT, Cook CL, O’Day K, Burch SP, Cantrell CR. How patient cost-sharing trends affect. P. T. 2012;37:45-55.

10. Ahuja J, Gupta M, Gupta AK, Kohli K. Pharmacoeconomics. Natl Med J India. 2004;17:803.

11. Sanchez LS. Pharmacoeconomics: Principles, methods and applications. In: Dipiro JT, Talbert RL, Yee GC, Matzke GR, Wells BG, Posey ML, eds. Pharmacotherapy: A pathophysiological approach. 7th ed. New York: McGraw Hill; 2008: 1-2.

12. Das SC, Mandal M, Mandal SC. A critical study on availability and price variation between different brands: impact on access to medicines. Indian $\mathbf{J}$ Pharm Sci. 2007;69(1):160-3.

13. Chawan VS, Gawand KV, Badwane SV. Cost analysis of oral hypolipidemic agents available in India. Int J Basic Pharmacol. 2014:3:954-7.
14. Thomas M. Rational drug use and essential drug concept. In: Parthasarthi G, Nyfort Hasen K, eds. A Textbook of Clinical Pharmacy Practice. 1st ed. Himayatnagar, Hyderabad: Orient Longman; 2004: 72.

15. Creese A, Kotwani A, Kutzin J, Pillay A. Evauating pharmaceuticals for health policy in low and middleincome country settings. In: Freemantle N, Hill S, eds. Evaluating pharmaceuticals for health policy and reimbursement. Massachusetts, USA: Blackwell Publication; 2004: 227-243.

16. Mahal A, Karan A, Engelgau M. The Economic Implications of Non-Communicable Disease for India. Washington, DC: World Bank; 2010.

17. Rataboli PV, Garg A. Confusing brand names: nightmare of medical profession. J Postgrad Med. 2005;51:13-6.

18. Drug Cost Control Order, 2013, Government of India. Available at: http://www.nppaindia.nic.in /DPCO2013. pdf. Accessed on 1 September 2019.

Cite this article as: Bhandari PR, Bhandary A. Variation of cost among anti-malarial drugs available in Indian market. Int J Basic Clin Pharmacol 2019;8:2408-11. 